\title{
Implementation of TQM Components to Improve the Productivity in SMEs
}

\author{
Dr. Meenakshi Tyagi \\ Assistant Professor KIET, Muradnagar
}

\begin{abstract}
The small and medium Enterprises have been playing an important role in the growth process of Indian economy since independence in spite of stiff competition from the large sector and not very encouraging support from the government. The essence of the argument that comes in mind is that despite playing a crucial role to contribute enormously in employment creation in the country, the SMEs are not well-equipped and working in traditional way to confront the challenges of global competition. Due to globalization, competition is very tough and big players have a strong grip on the market as they are prosperous in each field whether it is money, management, machinery or methods. Now SMEs have to compete with these big players so traditional approach is inadequate for the purpose. They need to work with TQM components to meet the challenges in the present context of global competition. The objective of this paper is to state the urgency of TQM to improve the productivity and quality level of SMEs by showing the result of those enterprises which have implemented TQM successfully. This study is capable to present the importance of TQM approach and provides positive direction for future work.
\end{abstract}

Keywords: Total Quality Management, SMEs, Cross Functional Team, Standard Operating Procedure

\section{Introduction}

Small and Medium Scale Enterprises (SMEs) have been fully recognized by governments and development experts as the main engine of economic growth and a major factor in promoting private sector development and partnership. In a developing country like India, the role and importance of SMEs is very significant towards poverty eradication, employment generation, rural development and creating regional balance in promotion and growth of various development activities. According to a report of financial year 2011 SMEs have contributed 17 percent to the GDP and employed 60 million people, the second largest workforce in the country after the agriculture sector. However SMEs, which constitute more than $90 \%$ of total number of industrial enterprises, are now facing a tough competition from their global counterparts due to liberalization, change in manufacturing strategies, technological changes, and turbulent and uncertain market scenario.

Despite governments institutional and policy supports aimed at enhancing the capacity of SMEs, SMEs have fallen short of expectation. This has generated serious concern and scepticism as to whether SMEs can bring about economic growth and national development. The low performance of SMEs has further exacerbated poverty, hunger, unemployment and low standard of living of people in the country. In order to produce quality product and increase productivity one must instil TQM concept into one's product development process.

\section{Productivity And TQM Defined:}

Productivity is a concept that has profound importance in our lives. The statement above reflects that this is the time to focus on productivity and productivity improvement. Productivity refers to the physical relation between the quality produced (output) and the quantity of resource used in the course of production (input). Productivity $(\mathrm{P})=$ output $(\mathrm{O})$ /input $(\mathrm{I})$

In TQM the word "Total" means involvement of all aspects of the organization to satisfy the customer. It covers every process, every job, every resource, every output, every person, every time and every place. 'Quality' word refers to what customer wants. It is customer's perception about the degree to degree to which the product or service meets his/ her expectation. Therefore, quality is defined by customer needs and expectations. Quality refers to fulfillment of specifications. Quality means fitness for use.

ISO defines-TQM is the management approach of an organization, centered on quality, based on the participation of all its members and aiming at long term success through customer satisfaction, and benefits to all members of the organization and to society.

According to the American Society for Quality Control (ASQC), total quality management (TQM) "is a management approach to long-term success through customer satisfaction. TQM is based on the participation of all members of an organization to improving processes, products, services, and the culture they work in. TQM benefits all organization members and society. The methods for implementing this approach are found in the teachings of such quality leaders as Philip B. Crosby, W. Edwards Deming, Armand V. Feigenbaum, Kaoru Ishikawa, and J.M. Juran." [Bemowski, 1992] 


\section{Review Of Literature}

TQM plays a crucial role to achieve the expected quality level of output in an organization. Total quality management is an integrative philosophy of management for continuously improving the quality of products and processes. It is rising above the system-oriented approach and makes the connection to the needs of the customers in the society and the improvement of the quality of the product and the organization as a whole (Rao \& Tang, 1996).

Kaoru Ishikawa [1976, 1985] took quality a step further in the 1960's and advocated that quality should be the responsibility of individual employee and that top management should provide quality leadership. He introduced the concept of Quality Control Circles.

Genichi Taguchi $[1986,1987]$ focused on the use of quantitative methods and design of experiments to improve quality, particularly in the area of product design.

In the late 1970's, Philip Crosby [1967,1969, 1979] began pushing zero defects as the default standard of performance, and not the exception. Under the TQM culture, the traditional goals of maximizing profit or benefit, minimizing costs, and achieving controlled growth have been replaced by improving customer satisfaction, improving quality, and reducing schedule.

TQM has the potential to not only increase competitiveness and organizational effectiveness but also improve product quality and organizational performance (Ahire, 1996).

Powell (1995) suggests that there are significant relationships between TQM, competitive advantage and business excellence.

TQM can be defined as a set of techniques and procedures used to reduce or eliminate variation from a production process or service-delivery system in order to improve efficiency, reliability, and quality (Steingrad \& Fitzgibbons, 1993).

A study conducted by Simmons and White (1999) shows that ISO 9000 registered companies are more competitive and profitable than non-ISO 9000 companies. The overall results point out the significant and positive impact of TQM on competitive advantage and customer satisfaction. This significantly improves the performance of these companies. Hence, quality is seen as a fundamental capability to develop an enterprise.

Vuppalapati, Ahire and Gupta (1995) stated that TQM is an integrative philosophy of management for the continuous improvement of product and process quality in order to achieve customer satisfaction.

Quality advocates have identified several critical principles for successful TQM practices like: top management role customer focus, supplier relationship, benchmarking, quality-oriented training, employee focus, zerodefects, process improvement and quality measurement (Saraph et al, 1989). Although, TQM is a wellestablished field of study for business excellence the success rate of TQM implementation is not very high. The major reason for TQM failure is owing to the tendency to look at TQM as tool and not as a system.

\section{Objective Of The Study}

The purpose of this paper is to present essence of TQM concept to improve the productivity by removing wastages and idle time that are the causes of increasing cost and sickness of SMEs.

\section{About The Case Study}

The data related to Susira Industries Ltd. Chennai, taken from Quality Council of India. The industry had won the D.L. Shah Award in the $6^{\text {th }}$ QCI Conclave to work with TQM Practices. Susira Industries Ltd (SIL), the flagship company of the group was established in the year 1976 by Mr. S. Seetharamaiah, a Mechanical Engineering Graduate and a first generation technocrat entrepreneur with a vast experience in the Indian Automobile Industry.

With his strong vision, undiluted commitment and dedication to TQM, he was able to quickly transform Susira, from a job-shop, into a world-class auto component manufacturer.

Today, Susira is a Multi-Million Dollar auto-component group, catering to the heavy and commercial vehicle segments of the Indian and World markets.

The base of this company is founded on 3Ps; means People, Process and Product which can be clearly seen in every aspect of their lives. 


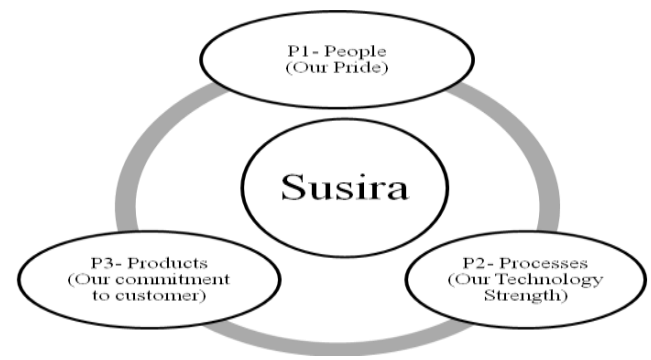

The company is already certified and India's $1^{\text {st }}$ SME to be certified for

- $\quad$ ISO 9002 in 1994

- $\quad$ QS 9000 in 1998

- $\quad$ ISO 14001 in 2002

- $\quad$ OHSAS 18001 in 2006

- $\quad$ NABL Accreditation for Lab in 2006

The present case study shows how the industry has reduced the Manufacturing cost in Induction Hardening operation by using TQM tools.

\section{Application Of Tqm System}

TQM is to identify and solve the problems to enhance customer satisfaction at an optimum cost, so a list of problems better to say opportunities for improvements were identified by using brainstorming technique, following problems were listed down in their operations-

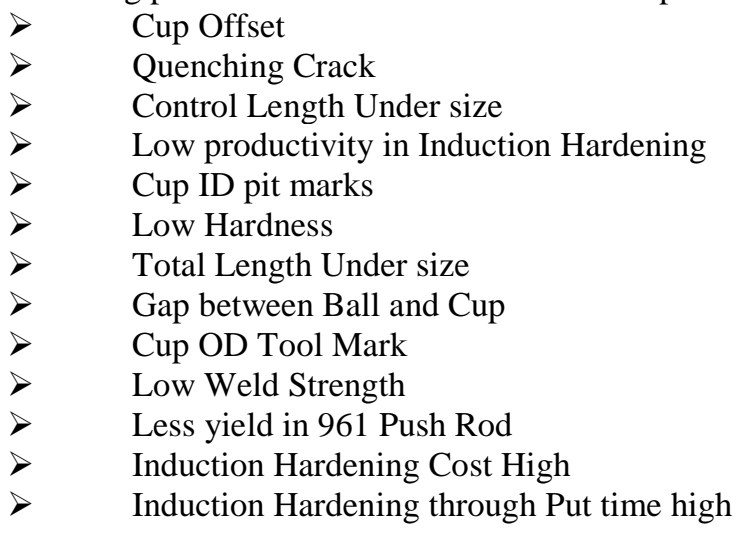

\section{Categorisation of Problems}

As TQM requires the involvement of each and every member of an organization to achieve the goal that is why the problems have been categorized into three parts.

\section{Category}

A

B

$\mathrm{C}$

\section{Description}

Minimum involvement of other departments in solving them Involvement of other department is necessary Management approval and support needed

\section{Below is the detail of categorized problems-}

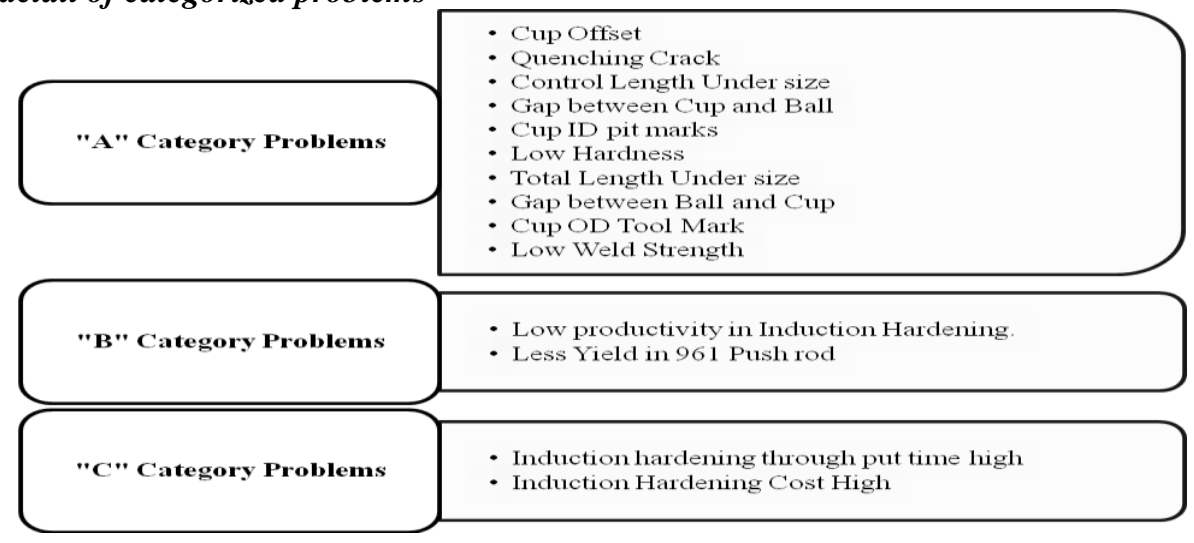




\section{ANALYSE PHASE}

Team decided to start with "B" Category problems first, to find out the root causes of Low productivity in Induction Hardening and to increase the Productivity in Induction Hardening Operation following TQM tools have been used in the organization

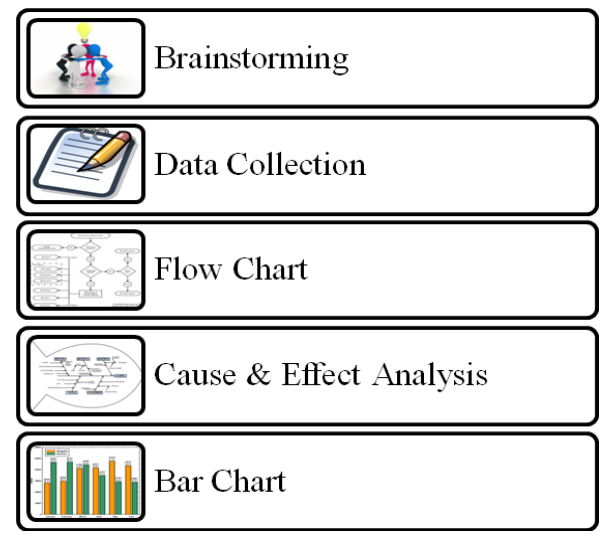

\section{Root Cause Analysis of low productivity in Induction Hardening (I/H) machine}

Cause and Effect analysis carried out to find out all possible causes, which are listed below for more clarity:

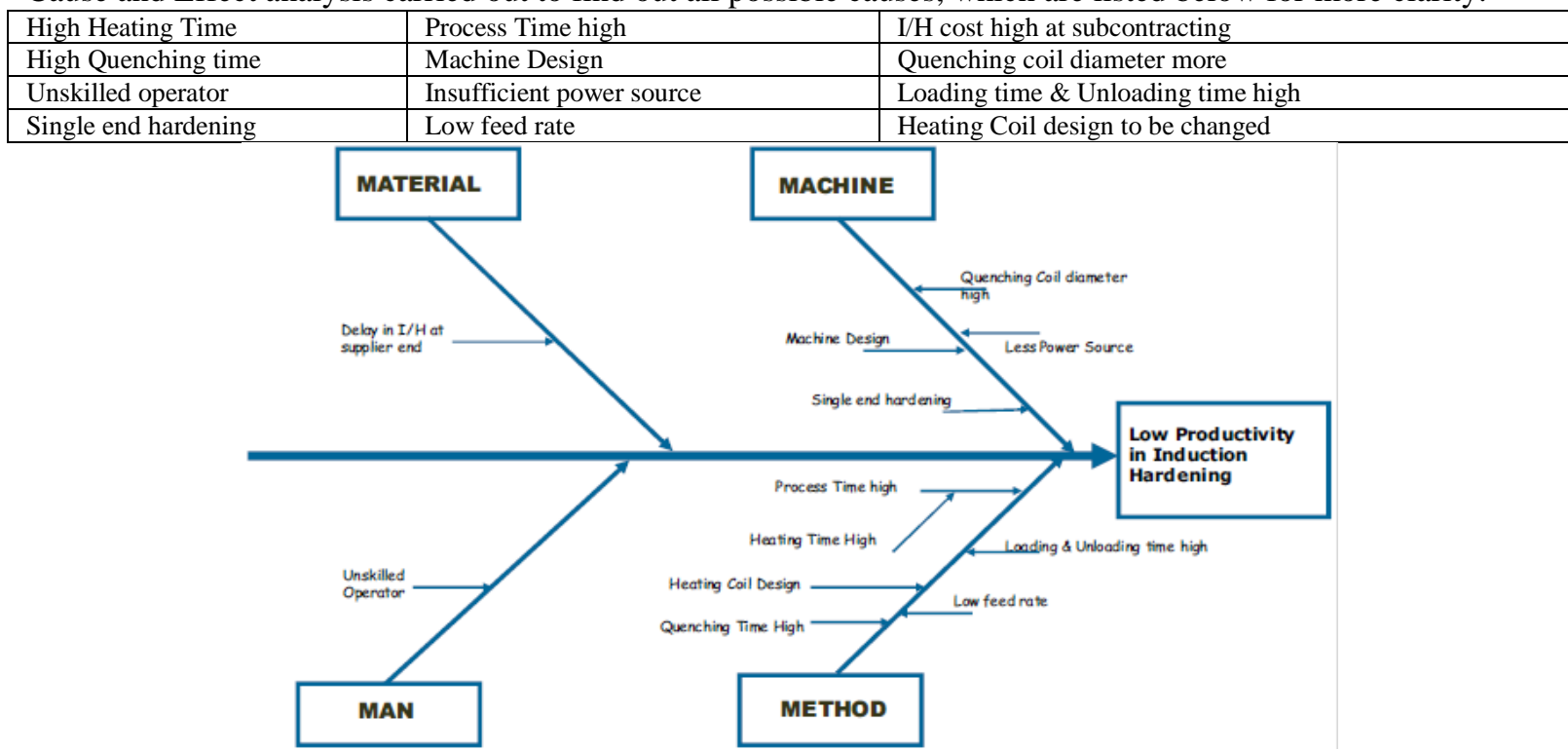

Further to analyse and to develop the solutions with the help of Cause and Effect Diagram a team exercise done (voting- based on past incidents and experience) to find the significant causes and all causes been divided into two categories- significant and insignificant, which are as follows: (High significant number - first to attack) (19 Scale, 9- Most Severe, Mostly occurred)

\begin{tabular}{|l|c|c|c|}
\hline Causes & Severity & Occurrence & Significant Number \\
\hline Delay in I/H at supplier end & 10 & 6 & 60 \\
\hline Machine designed with single end hardening & 8 & 5 & 40 \\
\hline Cycle time found to be high & 7 & 7 & 49 \\
\hline Loading and unloading time found to be high & 7 & 8 & 56 \\
\hline Quenching coil diameter verified found as per drawing & 5 & 4 & 20 \\
\hline $\begin{array}{l}\text { Quenching time verified as per the Standard Operating } \\
\text { Procedure (SOP) }\end{array}$ & 5 & 3 & 15 \\
\hline Heating coil design verified as per the SOP & 4 & 4 & 16 \\
\hline Heating time verified as per the SOP & 4 & 3 & 12 \\
\hline Feed rate verified as per the SOP & 2 & 2 & 4 \\
\hline
\end{tabular}



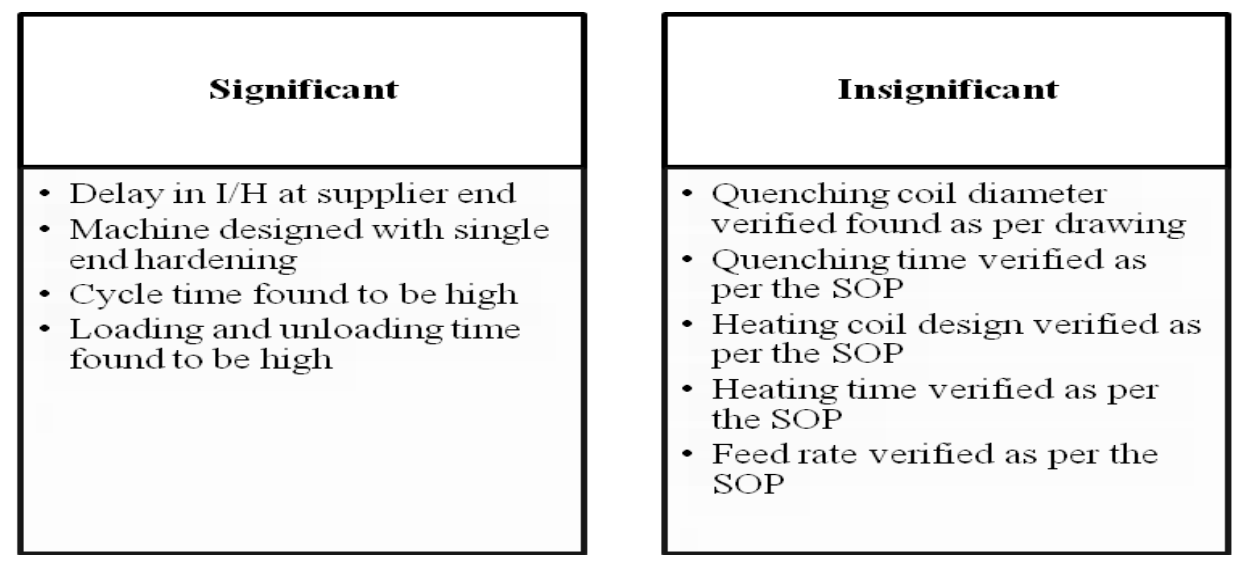

Significant causes considered to develop solutions and solutions were developed which are as follows: Low productivity in $\mathrm{I} / \mathrm{H}$ is due to less production at supplier end, high cycle time, single end $\mathrm{I} / \mathrm{H}$ and machine designed with single end induction hardening facility so to overcome the problem machine to be modified with double end induction hardening and additional features to reduce the cycle time

\begin{tabular}{|l|l|l|}
\hline Solution & Action to be Taken & $\begin{array}{l}\text { Responsibility\& Target } \\
\text { Status }\end{array}$ \\
\hline $\begin{array}{l}\text { Machine to be modified with double } \\
\text { end induction hardening and additional } \\
\text { features to reduce cycle time }\end{array}$ & $\begin{array}{l}\text { 1) Additional features for the new machine to CFT } \\
\text { be identified by CFT } \\
\text { (Cross Functional Team) }\end{array}$ & $\begin{array}{l}\text { 2) New machine design with improved } \\
\text { features such as conveyer type, drop quench, Channel } \\
\text { type coil. will be finalized jointly with the machine } \\
\text { manufacturer and action will be initiated for CFT } \\
\text { procurement }\end{array}$ \\
\hline
\end{tabular}

\section{Brainstorming to design the new machine:}

As team decided to modify the existing machine; team again brainstormed to find out the essential changes which should be done in machine and listed as given:

- Double end Induction Hardening done simultaneously

$\circ \quad$ Horizontal loading

- Continues feeding

- Conveyer type

$\circ \quad$ Drop quenching

$\circ \quad$ Cone type Coil

$\circ \quad$ Polymer quenching

- Poke Yoke system

$\circ \quad$ Required power source

$\circ \quad$ Adjustable Feed rate control

Entire team worked very hard for 3 weeks and did some changes, which are given here: Improved features in modified machine

- Both ends simultaneously Induction Hardened

- Continuous feeding with adjustable feed rate

- Drop quenching

○ Poke yoke system for power drop, power failure and heating station trip

$\circ \quad$ Independent heating control for cup \& ball end induction hardening

- Cycle time - the above features leading to reduced cycle time 


\section{Results \& A Comaparative Study}

A comparative study of various critical factors is given below to see the impact of solutions

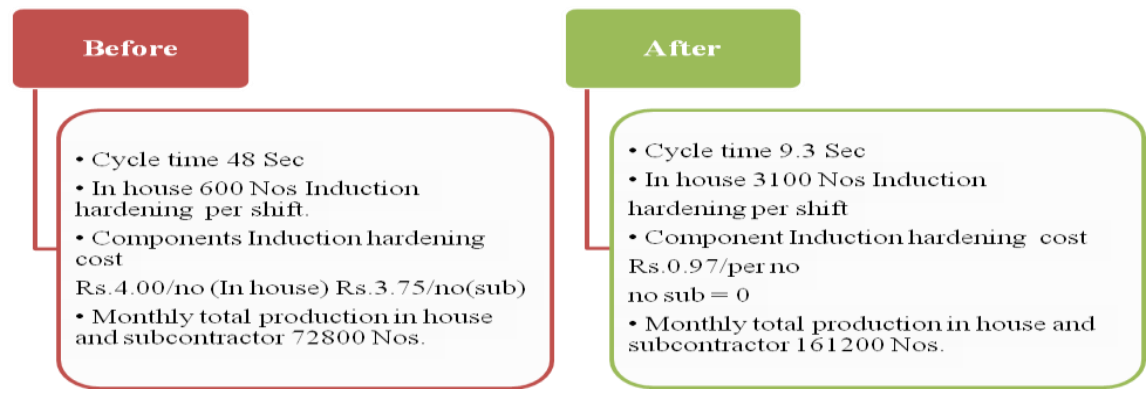

\section{PRODUCTIVITY COMPARISON}

\begin{tabular}{|l|l|l|l|}
\hline \multicolumn{1}{|c|}{ Description } & \multicolumn{1}{|c|}{$\begin{array}{c}\text { In house I/H Machine } \\
\text { (Scanner) }\end{array}$} & \multicolumn{1}{c|}{$\begin{array}{c}\text { Subcontractor I/H Machine } \\
\text { (Scanner) }\end{array}$} & $\begin{array}{c}\text { After Implementation In house } \\
\text { HF Machine }\end{array}$ \\
\hline Shift Rate & 2400 & 3000 & 3000 \\
\hline Per shift production & 600 & 800 & 3100 \\
\hline Per Day Production (2 Shift) & 1200 & 1600 & 6200 \\
\hline Cost per Component & 4 & 3.75 & 0.97 \\
\hline $\begin{array}{l}\text { Requirement per annum (900000 } \\
\text { No.) }\end{array}$ & 3600000 & 3375000 & 870968 \\
\hline Cost Saving per year & & & $\mathbf{2 7 2 9 0 3 2}$ \\
\hline
\end{tabular}

Graphical trend of cost per lakh and production is given below

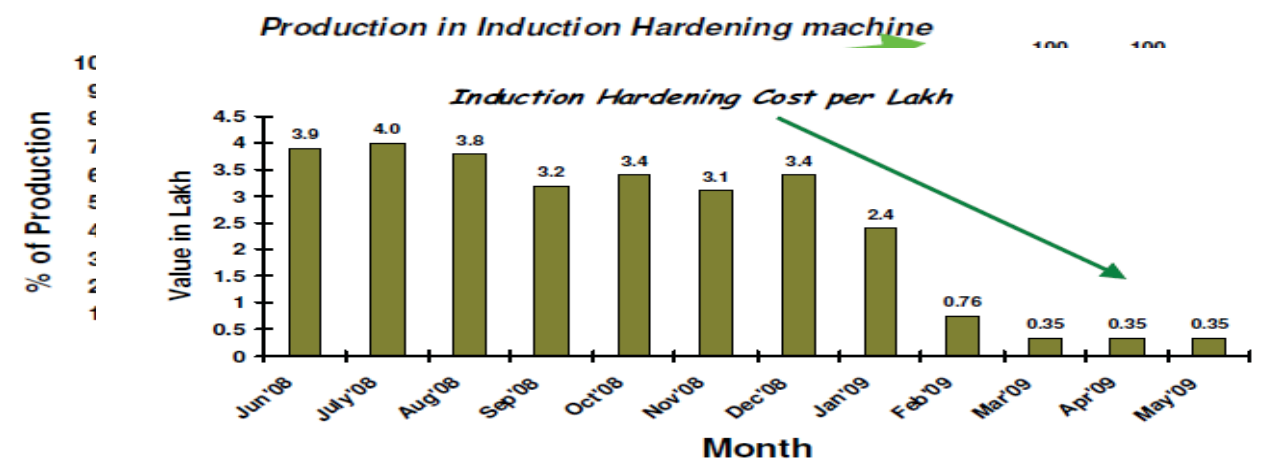

\section{(5) SUSIRA INDUSTRIES LTD In-house Production}

(Sources: Quality Council of India)

\section{Quick Summary Of Tangible Benefits}

A quick summary of tangible benefits is given here, which is very satisfactory in terms of savings; this saving can be transferred to customers in order to enhance customer satisfaction, which was not possible without systematic application of TQM system-

- Productivity Increased from 1200 nos. to 6200 nos. per day

- Push rod for Induction hardening Cost Rs.3.03 per push rod saved

- Rs. 227419.00 per month saving

$\circ \quad$ Rs .27, 29,032.00 per year saving

$\circ \quad$ Subcontracting totally eliminated

\section{Conclusion}

SMEs play a significant role in sustaining a developing nation's growth; the aim of this study was to investigate the extent to which the criteria of TQM have been attained in SMEs with particular reference to the selected company Susira Industries Ltd. Chennai. The result presented and discussed, the level of TQM implementation in Susira Industries Ltd. Chennai is a benchmark for other SMEs. To increase the chance of success, a TQM implementation project should start from the top management and unfold it downward to lowerlevel management and workers with a goal to benefit all stakeholders, also the goal is to improve the quality of 
work life for the employees with higher productivity and Zero Defects through successful implementation of TQM philosophies.

\section{References}

[1]. Ahire, S., Waller, M.A. and Glohar, D.Y. (1996), Quality management in TQM versus non TQM firms: an empirical investigation, Production and Inventory Management Journal, Vol. 37 No. 1, pp. 18-23. Business Today, India, September 10, 2006.

[2]. Dale, B., G. \& Duncalf A. J.(1984), A Study of Quality Assurance in Small Business, Proceeding of the Institute of Mechanical Engineering, 1984. PP 135-139

[3]. Deming, W.E.. (1986), Out of Crises, Cambridge, MA: MIT Center for Advance Engineering

[4]. Economic Survey Report of Maharashtra, 2006-07

[5]. Felipe F. Baesler. Milton Morage \& Francisco J.Ramis (2002) 'Productivity improvement in the wood industry using simulation and artificial intelligence', winter simulation conference, pp. 1095-1098.

[6]. Gobell, D. \& Shea, J. (1995), TQM: The Experience of 10 small Business, Business Horizons, Vol. 2, pp 125-135.

[7]. Lewis, W.G., Pun, K.F., T.R.M. (2005), Case Study: An AHP-based study of TQM benefits in ISO 9000 certified SMEs in Trinidad and Tobago, The TQM Magazine, Vol. 17 No. 6, pp. 558-572.

[8]. Luzan, M. (1993), Can total quality management make small business competitive?, Journal of Total Quality Management, Vol.4 No.2, pp. 105-181.

[9]. Rao, V., M., Tang, C., L. (1996), Strategic quality management, Malcolm Baldrige and European quality awards and ISO 9000 certification. International Journal of Quality and Reliability Management, Vol. 13,pp. 8-38.

[10]. Richard A. Reid (2006) 'Productivity and quality improvement: An implementation Framework', International Journal of Productivity and Quality Management Vol. 1, pp. 26-36.

[11]. Satty, T.L. (1980), Analytic Hierarchy Process, McGraw-Hill, New York.

[12]. Satty, T.L. (1987), Concept, theory and techniques:Rank Generation, preservation and reversal in the analytic hierarchy process, Decision Science, Vol. 18,pp. 157-172.

[13]. Seraph, JV, Benson, PG \& Schroeder, R.C. (1989), 'An instrument for measuring the critical factors of TQM', Decision Sciences, vol. 20, no. 4,pp.810-829.

[14]. Sils. I and Ebrahimpour, M. (2002), An investigation of the total quality management survey. Based research published between 1989 and 2000, International Journal of Quality and Reliability Management, Vol, 19 N0.7, pp 902-70.

[15]. T.Y, Hachkowski. P.A, Strong. D \& Mann. D.D (2006) 'Defect Analysis for Quality and Productivity Improvements in A Manufacturing System', Canadian Biosystems Engineering Vol.48, pp. 7.9-7.12.

[16]. Web site - Quality Council of India (www.qcin.org) 